\title{
Smoking related attitudes, motives, and behaviors of male secondary school students in an urban setting of China
}

\author{
Xianglong $\mathrm{Xu}^{1,2,3 \dagger}$, Cheng Chen ${ }^{1,4 \dagger}$, Abu S. Abdullah ${ }^{5,6,7}$, Lingli Liu ${ }^{1,2,3}$, Manoj Sharma ${ }^{8}$, Yaping Li1,2,3 \\ and Yong Zhao ${ }^{1,2,3^{*}}$
}

\begin{abstract}
Background: Most smokers have their first experience of cigarette use when they are teenagers (i.e. at schools). Aiming tobacco control initiatives at secondary school students offers preventive measures to eliminate or reduce tobacco use initiation by students. This study assessed smoking-related attitudes, motives and behavior as well as other factors associated with smoking among male secondary school students in an urban setting in China.
\end{abstract}

Methods: A cross-sectional survey was conducted in urban areas of Chongqing using a structured questionnaire administered to 1297 male secondary school students. Logistic regression analysis was employed to investigate the factors that affect smoking.

Results: Of the participants ( $n=1297), 27.7 \%$ were secondary and $72.3 \%$ were middle school students. Overall, $30.5 \%$ of the participants were smokers. The majority of the students procured their first cigarette from friends. The motivations of middle school students to smoke their first cigarette were curiosity (70.5\%) and imitation (13.1\%). The motivations of high school students for smoking their first cigarette were to satisfy their curiosity (51.8\%), relief of stress and social pressures (17.1\%), and imitation of smoker friends (15.9\%). Respondents from poor family financial conditions were more likely to smoke than those from rich family financial conditions [odds ratio (OR) 1.59, 95\% confidence intervals (CI) 1.00, 2.52]. Respondents whose fathers were smokers were more likely to smoke than those whose fathers were non-smokers (OR 1.65, 95\% Cl 1.25, 2.17). Respondents who had one or two smoker friends (OR $2.98,95 \% \mathrm{Cl} 1.93,4.60)$ and three or more smoker friends (OR $5.92,95 \% \mathrm{Cl} 4.35,8.05)$ were more likely to smoke than those who did not have any. Respondents who were neutral (OR $0.43,95 \% \mathrm{Cl} 0.20,0.91)$ and disagreed about the item "friends smoking" (OR $0.18,95 \% \mathrm{Cl} 0.08,0.39$ ) were less likely to smoke than those who agreed with the item.

Conclusions: This study indicates that male students who have negative attitudes toward smoking, who do not have a father or friends who smoke, and are from affluent backgrounds exhibit low tendency to start smoking at a young age. This study provides some implications for tobacco control policies among male secondary school students in urban settings.

Keywords: Attitudes, Smoking behaviors, Urban, Male, Secondary school students

\section{Background}

Tobacco use is becoming one of the major preventable causes of premature death, disease, and disability

\footnotetext{
*Correspondence: zhaoyong@cqmu.edu.cn; zhaoyongzb@qq.com

${ }^{\dagger}$ Xianglong $\mathrm{Xu}$ and Cheng Chen are joint first authors.

${ }^{1}$ School of Public Health and Management, Chongqing Medical University, Chongqing 400016, China

Full list of author information is available at the end of the article
}

globally (National Center for Chronic Disease Prevention and Health Promotion and U.S. Office on Smoking and Health 2014). Most of smokers are men, and almost 800 million men smoke, with a third of all smokers living in China (Mackay 2012). Smoking among teenagers is becoming a serious public health problem. Data from the Global Youth Tobacco Survey (GYTS) showed that, 16.2$30.1 \%$ teenagers initiated smoking and $8.6-14.6 \%$ had 
smoked (Warren et al. 2000). Approximately $90 \%$ of adult smokers began smoking before reaching 18 years old in the US (U.S. Department of Health and Human Services 2012), and approximately $40 \%$ of adolescent smokers in China started smoking before reaching 10 years old (Hesketh et al. 2001). In 2012, 52.9\% of male were smokers, and $31.0 \%$ of male smokers never seriously thought of quitting smoking in China (Xu et al. 2015). Tobacco control among adolescents is necessary and important to prevent many long-term diseases associated with smoking (U.S. Department of Health and Human Services 1994, 2012).

Based on the 2014 China Youth Tobacco Survey Report, overall $6.9 \%$ of junior middle and high school students smoked; the prevalence in male students $(11.2 \%)$ was higher than in female students (2.2\%) (China Center for Disease Control and Prevention 2014). A systematic review of smoking initiation among Asian adolescents showed that male youths were more likely to initiate smoking (Talip et al. 2016). Teenagers are in the period of growth and development, when all physiological systems and organs are not yet fully developed; thus, their unique physiological characteristics make them more susceptible to tobacco (Centers for Disease Control and Prevention 1994).

Tobacco exposure in early age indicates that the age of onset of numerous disease processes may be earlier and the incidence may be higher (WHO 2015). In particular, middle school is an important stage of physical and mental development. Cognition and the use of tobacco significantly affect tobacco control and smoking status (Treacy et al. 2007; Guo et al. 2012). The smoke-free campus policy can prevent non-regular smokers in high school from becoming regular smokers in college (Butler et al. 2012). Changing the social environment through policies and decreasing exposure of non-smoking students to tobacco use may decrease smoking initiation (Ridner 2005).

Although numerous studies have documented rates and risk factors of smoking among adults, reliable evidence of those pertaining to youth from China is minimal. Many studies have explored the factors associated with smoking, but smoking initiation and tobacco use among youth in developing countries is rarely addressed. Clarifying the factors that affect smoking among youth is necessary to reduce smoking in China. Considering how smoking cessation poses challenges for many smokers (Lina et al. 2016), encouraging and educating male teenagers to not start smoking tobacco has significant public health benefits. Investigating the association between smoking initiation and relevant characteristics can assist in developing novel tobacco control measures. Smoking prevention among teenagers can also bring lifelong health benefits. This study assessed smoking-related attitudes and behaviors as well as factors associated with smoking initiation among male secondary school students to address the following four research questions:

1. What is the motivation to smoke for the first time?

2. How is the first cigarette procured?

3. What are the related attitudes, motives and behaviors toward smoking?

4. What are the factors that affect smoking?

\section{Methods}

\section{Participants}

The study design and methods, including the inclusion criteria and the exclusion criteria and the population, as well as the survey administration, pilot study and methods of data collection have been reported previously (Xu et al. 2016). In June 2014, a formal investigation was conducted in the main urban areas of Chongqing. Among 1370 respondents, 1297 (94.7\%) people answered all the questions, and 73 questionnaires were excluded because of missing data, resulting in a final sample of 1297 for analysis. In the Chinese education system, grades 7-9 comprise junior middle school, and grades 10-12 are high school. Considering the low prevalence of smoking in female students, this study only focused on male students to investigate typical smoking-related characteristics. Research on smoking among youth has traditionally included both middle and high schools students (Holmberg and Hellberg 2007). We obtained written informed consents from all parents or main caregivers of the enrolled students through parent-teacher conferences. The study was conducted in accordance with the Declaration of Helsinki, and the protocol was approved by the Ethics Committee of Chongqing Medical University.

\section{Questionnaire content}

The questionnaire was derived from the 2014 China Youth Tobacco Survey Report (China Center for Disease Control and Prevention 2014). The questionnaire was customized for the target population based on the pilot study, and the final draft of the questionnaire was agreed upon after several discussions with experts and the pilot investigators. The questionnaire was piloted on 50 participants in one of the schools for finalization. We modified the questionnaire based on the results of the pilot study, especially the presentation of questions and the answer options.

\section{Demographics}

Demographic data included age, school status (middle/high school students), smoking status of parents (non-smoker/smoker), family structure (intact family/ non-intact family), per capita household income [high 
(>US\$750), average (US\$225-\$750), and low ( $<$ US\$225)]. The definition of intact family meant teenagers live with both biological parents, and non-intact family is defined as family with the absence of one or both biological parents.

\section{Smoking status}

Smoking status of students and parents were included. The number of smoking friends and family members were also included. Smoking status was determined by one item which asks respondents whether they were smokers. Current smoker was defined as a person who smoked any form of tobacco at the time of the interview. The method used to assess the smoking status of parents was conducted the same way. Participants were asked the following questions: "Does your father smoke? (yes/no)" and "Does your mother smoke? (yes/no)."

\section{Smoking-related attitudes}

Smoking-related attitudes were determined by their agreement on the following statements: (1) decided not to smoke in the future, (2) proud of being a non-smoker, (3) supported others not to smoke, (4) concerned about my health, (5) had confidence to refuse to smoke, and (6) looked for ways to refuse to smoke or quit smoking.

\section{Smoking-related behaviors}

A few questionnaire items measured their smokingrelated behaviors by the responses to "the way to obtain the first cigarette," "motivation to smoke for the first time," "supported smoking ban in public places (yes/no)," and "tried to quit smoking (yes/no)."

\section{The way to obtain the first cigarette}

The way to obtain the first cigarette included "friends gave it to me," "took it from home by myself," "parents gave it to me," "bought it by myself," and "other ways."

\section{Smoking motives}

The motivation to smoke for the first time included "imitation of smoker friends," "influenced by film or television," "rebellious psychology," "relieve stress and social pressures," and "other reasons." Social pressure came from peers, schoolwork, parents, teachers, and ego development. After "other ways" and "other reasons", blank spaces were provided for students to write related information.

\section{Data analyses}

Participant characteristics were summarized using frequencies, percentages and descriptive analysis (means, standard deviations, and percentages). Chi square tests were used to compare differences in categorical variables, and the $t$ tests were used to compare differences in continuous variables. Logistic regression analysis was employed to determine factors that affect smoking among male secondary school students. All statistics were performed using two-sided tests, and statistical significance was considered at $\mathrm{p}<0.05$. All data were analyzed with Statistical Package for Social Sciences (IBM-SPSS), Version 22.0.

\section{Results}

\section{Characteristics of participants}

The participants included 1297 males, of which 359 (27.7\%) were middle school students and 938 (72.3\%) were high school students. Among the participants, 395 (30.5\%) were smokers. The smoking rate was $35.6 \%$ and $17.0 \%$ for high and middle schools students, respectively. Compare with middle school students, the smoking rate of high school students was statistically higher than $(p<0.001)$. The smoking rate of the fathers of smokers was statistically higher than that of fathers of non-smokers $(p<0.001)$. The differences on maternal smoking status $(\mathrm{p}=0.01)$, socioeconomic status $(\mathrm{p}<0.001)$, and number of smoking friends and family members between smokers and non-smokers $(\mathrm{p}<0.05)$ were statistically significant (see Table 1).

\section{Smoking-related attitude}

A higher proportion of non-smokers (91.1\%) than smokers $(66.8 \%)$ responded that they had "decided not to smoke in the future," $(\mathrm{p}<0.001)$. Non-smokers had a more negative attitude toward smoking than smokers, and the former was "proud of being a non-smoker" ( $\mathrm{p}<0.001)$, "supported others not smoke" $(\mathrm{p}<0.001)$, "concerned about my health" ( $\mathrm{p}<0.001)$, "had confidence to refuse smoking" ( $\mathrm{p}<0.001$ ), and "looked for ways to refuse or quit smoking" $(\mathrm{p}<0.001)$ (see Table 2$)$.

\section{Smoking-related behaviors}

Non-smokers scored a higher percentage of "encouraged others not to smoke $(\mathrm{p}<0.001)$ " and "tried to get parents to quit smoking $(\mathrm{p}=0.04)$ " than smokers. However, no statistically significant difference was observed on "supported smokers to quit smoking" and "Tried to get friends to quit smoking" between non-smokers and smokers (see Table 3).

\section{Smoking-related behaviors among smokers}

Statistically significant differences were observed on "the way to obtain the first cigarette" $(p=0.001)$ and "motivation to smoke for the first time" $(\mathrm{p}=0.01)$ between high and middle school students. Middle school students obtained the first cigarette when friends provided it $(44.3 \%)$, took it from home by themselves $(16.5 \%)$, and 
Table 1 Characteristics of the sample (n, \%)

\begin{tabular}{|c|c|c|c|}
\hline Variables & Smoker $(n=395)$ & Non-smoker $(n=902)$ & p-value \\
\hline Age (mean $\pm S D)$ & $16.5 \pm 1.4$ & $15.4 \pm 1.9$ & $<0.001^{*}$ \\
\hline School status & & & $<0.001^{*}$ \\
\hline Middle school & $61(15.4)$ & $298(33.0)$ & \\
\hline High school & $334(84.6)$ & $604(67.0)$ & \\
\hline Family structure & & & 0.336 \\
\hline Intact family & $323(81.8)$ & $760(84.3)$ & \\
\hline Non-intact family & $69(17.5)$ & $139(15.4)$ & \\
\hline Missing & $3(0.8)$ & $3(0.3)$ & \\
\hline Per capita household income & & & $<0.001^{*}$ \\
\hline High & $57(14.4)$ & $171(19.0)$ & \\
\hline Average & $244(61.8)$ & $583(64.6)$ & \\
\hline Low & $94(23.8)$ & $148(16.4)$ & \\
\hline Paternal smoking status & & & $<0.001^{*}$ \\
\hline Non-smoker & $140(35.4)$ & $449(49.8)$ & \\
\hline Smoker & $255(64.6)$ & $453(50.2)$ & \\
\hline Maternal smoking status & & & $0.007^{*}$ \\
\hline Non-smoker & $370(93.7)$ & $874(96.9)$ & \\
\hline Smoker & $25(6.3)$ & $28(3.1)$ & \\
\hline The number of smoking friend & & & $<0.001^{*}$ \\
\hline None & $80(20.3)$ & $310(34.4)$ & \\
\hline One or two & $257(65.1)$ & $520(57.7)$ & \\
\hline Three or more & $58(14.7)$ & $72(8.0)$ & \\
\hline The number of smoking family member & & & $<0.001^{*}$ \\
\hline None & $82(20.8)$ & $582(64.5)$ & \\
\hline One or two & $48(12.2)$ & $99(11.0)$ & \\
\hline Three or more & $265(67.1)$ & $221(24.5)$ & \\
\hline Attitude towards friends smoking & & & $<0.001^{*}$ \\
\hline Agree & $47(11.9)$ & $24(2.7)$ & \\
\hline Neutral & $246(62.3)$ & $323(35.8)$ & \\
\hline Disagree & $102(25.8)$ & $555(61.5)$ & \\
\hline Attitude towards family member smoking & & & $<0.001^{*}$ \\
\hline Agree & $29(7.3)$ & $20(2.2)$ & \\
\hline Neutral & $168(42.5)$ & $222(24.6)$ & \\
\hline Disagree & $198(50.1)$ & $660(73.2)$ & \\
\hline
\end{tabular}

* Statistically significant $(p<0.05)$

other ways (21.3\%). More high school students obtained the first cigarette when friends provided it (62.3\%), took it from home by themselves (18.6\%), and other ways (8.1\%). According to the answers of a few participants, other ways of obtaining the fist cigarette included "stealing it from family members" and "obtaining it from a party with friends". Among the high school students, 93.4\% supported smoking ban in public places, which was statistically higher than $75.2 \%$ of middle school students $(p=0.02)$. A total of $62.3 \%$ of middle and $58.6 \%$ of high school students tried to quit smoking $(\mathrm{p}=0.60)$ (see Table 4).

\section{Smoking-related motives among smokers}

The motivations of middle school students to smoke for the first time were curiosity (70.5\%), imitation of smoker friends $(13.1 \%)$, and other reasons $(11.5 \%)$. The motivations of high school students to smoke for the first time were to satisfy curiosity (51.8\%), relieve stress and social pressures (17.1\%), and imitate smoker friends (15.9\%). Some students chose other motivations, such as "forced by roommates", "for recreation and entertainment" (see Table 4). 
Table 2 Smoking-related attitude (n, \%)

\begin{tabular}{|c|c|c|c|}
\hline Variable & Smoker $(n=395)$ & Non-smoker $(n=902)$ & p-value \\
\hline Decided not to smoke in the future & & & $<0.001^{*}$ \\
\hline Agree & $264(66.8)$ & $822(91.1)$ & \\
\hline Neutral & $94(23.8)$ & $62(6.9)$ & \\
\hline Disagree & $37(9.4)$ & $18(2.0)$ & \\
\hline Proud of being a non-smoker & & & $<0.001^{*}$ \\
\hline Agree & $254(64.3)$ & $783(86.8)$ & \\
\hline Neutral & $86(21.8)$ & $90(10.0)$ & \\
\hline Disagree & $55(13.9)$ & $29(3.2)$ & \\
\hline Supported others not to smoke & & & $<0.001^{*}$ \\
\hline Agree & $273(69.1)$ & $777(86.1)$ & \\
\hline Neutral & $81(20.5)$ & $99(11.0)$ & \\
\hline Disagree & $41(10.4)$ & $26(2.9)$ & \\
\hline Concerned about my health & & & $<0.001^{*}$ \\
\hline Agree & $351(88.9)$ & $875(97.0)$ & \\
\hline Neutral & $28(7.1)$ & $22(2.4)$ & \\
\hline Disagree & $16(4.1)$ & $5(0.6)$ & \\
\hline Had confidence to refuse to smoke & & & $<0.001^{*}$ \\
\hline Agree & $294(74.4)$ & $827(91.7)$ & \\
\hline Neutral & $76(19.2)$ & $61(6.8)$ & \\
\hline Disagree & $25(6.3)$ & $14(1.6)$ & \\
\hline Looked for ways to refuse to smoke or quit smoking & & & $<0.001^{*}$ \\
\hline Agree & $286(72.4)$ & $794(88.0)$ & \\
\hline Neutral & $75(19.0)$ & $91(10.1)$ & \\
\hline Disagree & $34(8.6)$ & $17(1.9)$ & \\
\hline
\end{tabular}

* Statistically significant $(p<0.05)$

Table 3 Smoking-related practices $(n, \%)$

\begin{tabular}{|c|c|c|c|}
\hline Variable & Smoker $(n=395)$ & Non-smoker $(n=902)$ & p-value \\
\hline Encouraged others not to smoke & & & $<0.001^{*}$ \\
\hline Yes & $284(71.9)$ & $732(81.2)$ & \\
\hline No & $111(28.1)$ & $170(18.9)$ & \\
\hline Supported smokers to quit smoking & & & 0.794 \\
\hline Yes & $277(70.1)$ & $626(69.4)$ & \\
\hline No & $118(29.9)$ & $276(30.6)$ & \\
\hline Tried to get friends to quit smoking & & & 0.293 \\
\hline Yes & $276(69.9)$ & $656(72.7)$ & \\
\hline No & $119(30.1)$ & $246(27.3)$ & \\
\hline Tried to get parents to quit smoking & & & $0.042^{*}$ \\
\hline Yes & $269(68.1)$ & $664(73.6)$ & \\
\hline No & $126(31.9)$ & $238(26.4)$ & \\
\hline
\end{tabular}

* Statistically significant $(p<0.05)$

\section{Logistic regression model to probe factors that affect smoking}

Students who lived within low socioeconomic status were 1.59 times more likely to try cigarettes than students who lived within high or average per capita household income [adjusted odds ratio (OR) were 1.59, 95\% confidence intervals (CI) were 1.00, 2.52]. Students whose fathers smoked were 1.65 times more likely to smoke than those whose fathers do not smoke (adjusted OR 1.65, 95\% CI $1.25,2.17)$. Students who had one to two friends who 
Table 4 Comparison of motives and behaviors among smokers between high school students and middle school students (n, \%)

\begin{tabular}{|c|c|c|c|c|c|}
\hline \multirow[t]{2}{*}{ Variable } & \multicolumn{2}{|c|}{$\begin{array}{l}\text { Middle school } \\
(n=61)\end{array}$} & \multicolumn{2}{|c|}{$\begin{array}{l}\text { High school } \\
(n=334)\end{array}$} & \multirow[t]{2}{*}{$p$-value } \\
\hline & Yes & Rank & Yes & Rank & \\
\hline
\end{tabular}

\begin{tabular}{|c|c|c|c|c|c|}
\hline \multicolumn{6}{|c|}{ The way to obtain the first cigarette } \\
\hline Friends gave it to me & $27(44.3)$ & 1 & $208(62.3)$ & 1 & $0.004^{*}$ \\
\hline $\begin{array}{l}\text { Took it from home by } \\
\text { myself }\end{array}$ & $10(16.4)$ & 3 & $62(18.6)$ & 2 & \\
\hline Parents gave it to me & $6(9.8)$ & 4 & $14(4.2)$ & 5 & \\
\hline Bought it by myself & $5(8.2)$ & 5 & $23(6.9)$ & 4 & \\
\hline Other ways & $13(21.3)$ & 2 & $27(8.1)$ & 3 & \\
\hline \multicolumn{5}{|c|}{ Supported smoking ban in public places } & $0.004^{*}$ \\
\hline Yes & $57(93.4)$ & 1 & $251(75.2)$ & 1 & \\
\hline No & $4(6.6)$ & 2 & $83(24.9)$ & 2 & \\
\hline Tried to quit smoking & & & & & $0.008^{*}$ \\
\hline Yes & $57(93.4)$ & 1 & $196(58.7)$ & 1 & \\
\hline No & $4(6.6)$ & 2 & $138(41.3)$ & 2 & \\
\hline \multicolumn{5}{|c|}{ The motivation to smoke for the first time } & $0.008^{*}$ \\
\hline Curious & $43(70.5)$ & 1 & $173(51.8)$ & 1 & \\
\hline $\begin{array}{l}\text { Imitation of smoker } \\
\text { friends }\end{array}$ & $8(13.1)$ & 2 & $53(15.9)$ & 3 & \\
\hline $\begin{array}{l}\text { Influenced by film or } \\
\text { television }\end{array}$ & $2(3.3)$ & 4 & $5(1.5)$ & 6 & \\
\hline $\begin{array}{l}\text { Rebellious psychol- } \\
\text { ogy }\end{array}$ & $1(1.6)$ & 5 & $13(3.9)$ & 5 & \\
\hline $\begin{array}{r}\text { Relieve stress and } \\
\text { social pressures }\end{array}$ & $0(0.0)$ & 6 & $57(17.1)$ & 2 & \\
\hline Other reasons & $7(11.5)$ & 3 & $33(9.9)$ & 4 & \\
\hline
\end{tabular}

* Statistically significant $(p<0.05)$

smoke were 2.98 times more likely to try cigarettes than students who did not have friends who smoke (adjusted OR $2.98,95 \%$ CI 1.93, 4.60), and students who had three or more friends who smoke were 5.92 times more likely to try cigarettes (adjusted OR 5.92, 95\% CI 4.35, 8.05). Students who disagreed (adjusted OR 0.18, 95\% CI 0.08, 0.39 ) or those who were neutral (adjusted OR 0.43, 95\% CI $0.20,0.91$ ) with regard to friends smoking were less likely to smoke than those who agree with friends smoking (Table 5).

\section{Discussion}

Knowledge, attitudes and practices (KAP) model has been widely used in public health. KAP model is based on the principle that increasing knowledge will result in changed attitudes and practices to minimize the burden of diseases (Mascie-Taylor et al. 2003). For example, a KAP study in Thailand showed the positive influence of increasing community knowledge on controlling and preventing dengue, thereby improving prevention practices (Koenraadt et al. 2006). What's more, some other surveys
Table 5 Logistic regression model for identifying factors that affect smoking among male secondary students

\begin{tabular}{lccc}
\hline Variable & OR & $\mathbf{9 5 \%} \mathbf{C l}$ & p-value \\
\hline $\begin{array}{l}\text { Per capita household income } \\
\text { High }\end{array}$ & 1 & & \\
Average & 1.25 & $(0.85,1.85)$ & 0.255 \\
Low & 1.59 & $(1.00,2.52)$ & $0.048^{*}$ \\
Father smoking status & & & \\
Non-smoker & 1 & & $0.001^{*}$ \\
Smoker & 1.65 & $(1.25,2.17)$ & \\
The number of smoking friend & & \\
None & 1 & & $<0.001^{*}$ \\
One or two & 2.98 & $(1.93,4.60)$ & $<0.001^{*}$ \\
Three or more & 5.92 & $(4.35,8.05)$ & \\
Attitude toward friends smoking & & $0.026^{*}$ \\
Agree & 1 & & $<0.001^{*}$ \\
Neutral & 0.43 & $(0.20,0.91)$ & \\
Disagree & 0.18 & $(0.08,0.39)$ & 0.281 \\
Attitude toward family member smoking & & 0.667 \\
Agree & 1 & & \\
Neutral & 1.63 & $(0.67,3.93)$ & $(0.50,2.92)$ \\
Disagree & 1.21 & & \\
\hline
\end{tabular}

$O R$ odds ratio, $\mathrm{Cl}$ confidence intervals

* Statistically significant $(p<0.05)$

adopted KAP model include identifying knowledge gaps, cultural beliefs, and behavioral patterns that may pose barriers to controlling infectious diseases (Krentel et al. 2006; Matibag et al. 2007), design of relevant public health awareness campaigns (Cantey et al. 2010), establishing baseline data for planning and implementation, and evaluating control program.

The rate of tobacco use among high school students is higher than that among middle school students. This survey showed that $30.5 \%$ of participants were smokers, in which the smoking rate of high school students was $35.6 \%$ whereas the smoking rate of middle school students was $17.0 \%$. A study in the US found that $8.3 \%$ of participants were current smokers (Adams et al. 2013), and a recent trial of a smoking prevention intervention study in Germany found less than $8.0 \%$ were regular smokers in the intervention group, and $10.1 \%$ in the control group (Krist et al. 2016). Compared with other countries, the situation of students smoking in China is heightened. A potential interpretation is that this study focused on male students and the definition that we used to define a smoker (i.e. smoking any cigarette in the past) was broad. A cross-sectional analysis in Canada showed that $28.1 \%$ of male students smoke and that one or more family members who smoke were considered as a risk factor (Gregoire et al. 2016). 
The prevalence of smoking among male students was lower than that among male adults, with a smoking rate of $52 \%$ (Xu et al. 2015). For adults, the time of exposure to tobacco use and smoking was longer, which was considered as a type of social propriety in China. These findings may contribute to the higher smoking rate in male adults than in male students. A previous study also showed that the rate trend of tobacco use significantly increased as the grade level increased in middle school students (China Center for Disease Control and Prevention 2014). The present study shows that non-smokers have a more negative attitude toward smoking than smokers. Another study demonstrated that establishing the right attitude toward tobacco control in middle school students was advantageous to reduce their smoking rate (Guo et al. 2012). Additionally, a previous study showed the combination of family opposed to smoking and peers who discourage smoking were advantageous to quitting smoking (Mak et al. 2012). Cooperation between schools and parents in providing smoking cessations measures is imperative to improve smoking cessation in middle and high school male smokers.

This study investigated the means to procure the first cigarette and motivation to smoke for the first time. Most students obtained their first cigarette from their friends or they took it from their home. This finding is similar to the positive association between smoker friends and smoking tendencies in Iranian high school students (Chaman et al. 2015). Teaching students how to uncompromisingly refuse is necessary when faced with the fist cigarette acquired from their friends. Curiosity also played a key role in the initial motivation. A previous study also found that curiosity significantly improved the identification and classification of which adolescents would experiment with smoking (Nodora et al. 2014). Similarly, the evidence in the present study shows that curiosity was the main reason male adolescents smoked for the first time. The other two important motivations include imitating smoker friends and relief of stress and social pressures.

Factors affecting smoking in secondary schools should be considered in tobacco control efforts. In this study, respondents who were from poor family financial conditions were more likely to smoke than were from rich family financial conditions. This finding is consistent with other findings that showed that tobacco use was strongly associated with adolescents living within a low socioeconomic status (SES) (Bird et al. 2016; Rosen et al. 2014). Adolescents with low SES might have received more negative influence from smoking parents or other household members about smoking and less support for not taking up smoking or in smoking cessation. Tobacco controls on secondary school students should focus on low-income families. This study also found that negative attitudes toward smoking behavior and parents who do not smoke are two factors that prevent adolescent smoking among Chinese secondary school students. Respondents whose fathers are smokers are more likely to smoke than those whose fathers are non-smokers, which further confirm that parents, especially fathers, have a significant influence on the smoking behavior of children (Wilkinson et al. 2008). Parents should set an example in front of their children and quit smoking as soon as possible to persuade children not to become a smoker (Clark et al. 2006).

Respondents who have friends who smoke are more likely to smoke. Therefore, the possibility of smoking increased with the number of friends who smoke, suggesting that the peers easily influence the behavior of students. Many studies have reported that peer pressure and fathers who smoke are important factors which influence the smoking of youth (Passey et al. 2011). Numerous examples of smokers in the environment, especially in the companion of a role model who smoke will increase the odds of the smoking behavior of a teenager (Hawkins et al. 1992; Keefe 1994). Therefore, improving the coping skills of secondary school students against peer pressure is important. This study also found that respondents who were neutral and disagreed with the item "friends smoking" were less likely to smoke than those who agreed. The negative attitudes of students toward smoking make them less likely to smoke because smoking-related attitudes influence smoking behavior. Therefore, strengthening tobacco control publicity is necessary for secondary schools to assist students in establishing the right attitude toward smoking. The future direction of tobacco control among middle school students is focused on smokingrelated attitudes and peer education.

The results of this study have a few important implications for school health. First, approximately 30.45\% of urban male secondary school students are smokers. Strengthening the work of tobacco control among male high school students is urgent. Comprehensive interventions, including individual, campus, family, community, and government strategies, can be used to reduce vulnerability in Chinese secondary school students. Second, many studies indicated that having friends who smoke had an effect on the smoking status of the student, the registered number of friends who smoke is associated with the smoking status of students, especially in most male students who obtained their first cigarette from their friends. This finding suggests peer pressure and influence from fellow classmates as important factors contributing to the initiation of smoking, and important areas to consider when planning smoking prevention programs. Peer education is necessary to inform male 
students regarding the method on refusing their first cigarette from friends. Third, a meaningful finding was that a considerable number of male students started to smoke because of curiosity. Therefore, reducing student curiosity on smoking and informing them regarding the harmful effects of smoking can play a pivotal role in future research. Fourth, students within low socioeconomic status are more likely to smoke, which suggests the need to adopt a protocol for screening and education by school nurses and teachers with regards to this student population. Moreover, negative attitudes toward smoking behavior were associated with the smoking behavior among male students. The current findings suggest that a comprehensive school-based tobacco control campaign is urgently required.

This study also has some limitations. First, $72.3 \%$ of the subjects are high school students, and only $27.7 \%$ of the subjects are middle school students, thereby affecting the representativeness of secondary school students. Therefore, this study requires cautious interpretation of the results, especially among middle school students. Second, only urban secondary students were investigated and rural secondary students were not investigated. In China, the smoking rate of rural secondary school students was higher than that of urban secondary school students (Butler et al. 2012). Replicating this study in rural secondary school students would be useful to assess the difference between the urban and rural students in China. Cautions will also be necessary to extrapolate the findings to students in other countries, given the socio-cultural differences between China and elsewhere. Finally, this study was cross-sectional and causal association cannot be confirmed. Moreover, the current study did not assess the tobacco use among female students, therefore, cautions will be necessary to extrapolate the findings to female students.

\section{Conclusions}

Overall, approximately $30.5 \%$ of urban male secondary school students were smokers. Students procured their first cigarette primarily from a friend, and the motive to smoke the first cigarette was curiosity. Students who started smoking at a young age were those who had positive attitudes towards smoking, had fathers who were smokers, had a smoker friend, and belonged to poor economic background. Comprehensive interventions, including individual, campus, family, community, and government strategies, can target risky behaviors in an effort to reduce smoking among Chinese secondary school students. These findings enhance the understanding of the epidemic of smoking among male secondary school students in an urban setting of China and should be incorporated into future youth tobacco control strategies.

\section{Authors' contributions}

All authors contributed to the design of the study. XX was responsible for literature searches, the interpretation of the results, and writing the manuscript. CC was responsible for data analysis, the interpretation of the results. XX, CC and $Y Z$ participated in the development of the study protocol, data collection. $X X, C C, A S A, L L, M S, Y L, Y Z$ contributed to the drafting of the manuscript. $Y Z$ was responsible for the conception of the study and overall supervision of the data collection and analysis, the interpretation of the results, and manuscript preparation. All authors read and approved the final manuscript.

\section{Author details}

${ }^{1}$ School of Public Health and Management, Chongqing Medical University, Chongqing 400016, China. ${ }^{2}$ Research Center for Medicine and Social Development, Chongqing Medical University, Chongqing 400016, China. ${ }^{3}$ Innovation Center for Social Risk Governance in Health, Chongqing Medical University, Chongqing 400016, China. ${ }^{4}$ Xiangya School of Public Health, Central South University, Changsha 410001, Hunan Province, China. ${ }^{5}$ Global Health Program, Duke Kunshan University, Kunshan 215347, Jiangsu Province, China. ${ }^{6}$ Duke Global Health Institute, Duke University, Durham, NC 27710, USA. ${ }^{7}$ Department of General Internal Medicine, School of Medicine, Boston University Medical Center, Boston, MA 02118, USA. ${ }^{8}$ Behavioral and Environmental Health, School of Public Health, Jackson State University, Jackson, MS 39213, USA.

\section{Acknowledgements}

We would like to thank team members for their support and contributions to this study. We would also like to thank Dr. Cesar Reis at Loma Linda University Medical Center for proofreading.

\section{Competing interests}

The authors declare that they have no competing interests.

\section{Ethical approval}

We obtained written informed consents from all parents or main caregivers of the enrolled children through parent-teacher conferences. The study was conducted in accordance with the Declaration of Helsinki, and the protocol was approved by the Ethics Committee of Chongqing Medical University.

\section{Funding}

This study was funded by Science and Technology Commission, Shapingba District, Chongqing, China (No. PJ20140047), Summer Social Practice Project of School of Public Health and Management, Chongqing Medical University. The study sponsor had no role in study design.

Received: 2 March 2016 Accepted: 18 November 2016

Published online: 28 November 2016

\section{References}

Adams ML, Jason LA, Pokorny S, Hunt Y (2013) Exploration of the link between tobacco retailers in school neighborhoods and student smoking. J Sch Health 83(2):112-118

Bird Y, Staines-Orozco H, Moraros J (2016) Adolescents'smoking experiences, family structure, parental smoking and socioeconomic status in Ciudad Juárez, Mexico. Int J Equity Health 15:29. doi:10.1186/s12939-016-0323-y

Butler KM, Rayens MK, Hahn EJ, Adkins SM, Staten RR (2012) Smoke-free policy and alcohol use among undergraduate college students. Public Health Nurs 29(3):256-265

Cantey PT, Rao G, Rout J, Fox LM (2010) Predictors of compliance with a mass drug administration programme for lymphatic filariasis in Orissa State, India 2008. Trop Med Int Health 15(2):224-231

Centers for Disease Control and Prevention (1994) Preventing tobacco use among young people-a report of the surgeon general. MMWR Recomm Rep 43(RR-4):1-10 
Chaman R, Khosravi A, Sajedinejad S (2015) Smoking and its related factors among Iranian high school students. Iran J Psychiatry Behav Sci 9(4):e1583

China Center for Disease Control and Prevention (2014) 2014 China Youth Tobacco Survey Report. China Center for Disease Control and Prevention, Beijing, pp 5-8 (In Chinese)

Clark PI, Schooley MW, Pierce B, Schulman J, Hartman AM, Schmitt CL (2006) Impact of home smoking rules on smoking patterns among adolescents and young adults. Prev Chronic Dis 3(2):A41

Gregoire B, Azagba S, Asbridge M (2016) Smoke-free homes, smoking susceptibility and familial smoking among never-smoking high school students: a cross-sectional analysis. CMAJ 4(2):E298-E303

Guo Q, Unger JB, Azen SP, Mackinnon DP, Johnson CA (2012) Do cognitive attributions for smoking predict subsequent smoking development? Addict Behav 37(3):273-279

Hawkins JD, Catalano RF, Miller JY (1992) Risk and protective factors for alcoho and other drug programs in adolescence and early adulthood: implications for substance abuse prevention. Psychol Bull 112(1):64-105

Hesketh T, Ding QJ, Tomkins A (2001) Smoking among youths in China. Am J Public Health 91(10):1653-1655

Holmberg LI, Hellberg D (2007) Health, health-compromising behavior, risktaking behavior and sexuality in female and male high school students in vocational compared with theoretical programs in Sweden. Int J Adolesc Med Health 19(4):459-472

Keefe K (1994) Perceptions of normative social pressure and attitudes toward alcohol use: changes during adolescence. J Stud Alcohol 55(1):46-54

Koenraadt CJM, Tuiten W, Sithiprasasna R, Kijchalao U, Jones JW et al (2006) Dengue knowledge and practices and their impact on Aedes aegypti populations in Kamphaeng Phet, Thailand. Am J Trop Med Hyg 74(4):692-700

Krentel A, Fischer P, Manoempil P, Supali T, Servais G et al (2006) Using knowledge, attitudes and practice (KAP) surveys on lymphatic filariasis to prepare a health promotion campaign for mass drug administration in Alor District, Indonesia. Trop Med Int Health 11(11):1731-1740

Krist L, Lotz F, Büger C (2016) Long-term effectiveness of a combined studentparent and a student only smoking prevention intervention among 7th grade school children in Berlin, Germany. Addiction. doi:10.1111/ add. 13537

Lina M, Mazza R, Borreani C (2016) Hospital doctors'smoking behavior and attitude towards smoking cessation interventions for patients: a survey in an Italian Comprehensive Cancer Centre. Tumori J 102(3):244-251

Mackay J (2012) Implementing tobacco control policies. Br Med Bull 102:5-16. doi:10.1093/bmb/lds007

Mak KK, Ho SY, Day JR (2012) Smoking of parents and best friend-independent and combined effects on adolescent smoking and intention to initiate and quit smoking. Nicotine Tob Res 14(9):1057-1064

Mascie-Taylor CGN, Karim R, Karim E, Akhtar S, Ahmed T et al (2003) The cost-effectiveness of health education in improving knowledge and awareness about intestinal parasites in rural Bangladesh. Econ Hum Biol 1:321-330

Matibag GC, Kamigaki T, Kumarasiri PVR, Wijewardana TG, Kalupahana AW et a (2007) Knowledge, attitudes, and practices survey of rabies in a community in Sri Lanka. Environ Health Prev Med 12:84-89
National Center for Chronic Disease Prevention and Health Promotion, U.S. Office on Smoking and Health (2014) The health consequences of smoking - 50 years of progress: a report of the surgeon general. Centers for Disease Control and Prevention, Washington

Nodora J, Hartman SJ, Strong DR (2014) Curiosity predicts smoking experimentation independent of susceptibility in a US national sample. Addict Behav 39(12):1695-1700

Passey ME, Gale JT, Sanson-Fisher RW (2011) "It's almost expected": rural Australian Aboriginal women's reflections on smoking initiation and maintenance: a qualitative study. BMC Women's Health 11:55. doi:10.1186/1472-6874-11-55

Ridner S (2005) Predicting smoking status in a college-age population. Public Health Nurs 22(6):494-505

Rosen L, Rozhavsk V, Levine H (2014) Smoking initiation among Israeli adolescents: a 24-year time-to-event analysis. Prev Med 65:141-147. doi:10.1016/j.ypmed.2014.05.020

Talip T, Murang Z, Kifli N, Naing L (2016) Systematic review of smoking initiation among Asian adolescents, 2005-2015: utilizing the frameworks of triadic influence and planned behavior. Asian Pac J Cancer Prev 17(7):3341-3355

Treacy MP, Hyde A, Boland J, Whitaker T, Abaunza PS, Stewart-Knox BJ (2007) Children talking: emerging perspectives and experiences of cigarette smoking. Qual Health Res 17(2):238-249

U.S. Department of Health and Human Services (1994) Preventing tobacco use among young people: a report of the surgeon general. U.S. Department of Health and Human Services, Centers for Disease Control and Prevention, Atlanta. http://www.cdc.gov/tobacco/data_statistics/sgr/1994/ index.htm. Accessed 26 Jul 2013

U.S. Department of Health and Human Services (2012) Preventing tobacco use among youth and young adults: a report of the surgeon general. U.S. Department of Health and Human Services, Centers for Disease Control and Prevention, Atlanta. http://www.cdc.gov/tobacco/data_statistics/ sgr/2012/index.htm. Accessed 26 Jul 2013

Warren CW, Riley L, Asma S, Eriksen MP, Green L, Blanton C, Loo C, Batchelor S, Yach D (2000) Tobacco use by youth: a surveillance report from the global youth tobacco survey project. Bull World Health Organ 78(7):868-876

WHO (2015) Fact sheet updated January 2015. Non-communicable diseases. http://www.who.int/mediacentre/factsheets/fs355/en/

Wilkinson AV, Shete S, Prokhorov AV (2008) The moderating role of parental smoking on their children's attitudes toward smoking among a predominantly minority sample: a cross-sectional analysis. Subst Abuse Treat Prev Policy 3:18. doi:10.1186/1747-597X-3-18

Xu X, Liu L, Sharma M (2015) Smoking-related knowledge, attitudes, behaviors, smoking cessation idea and education level among young adult male smokers in Chongqing, China. Int J Environ Res Public Health 12(2):2135-2149

Xu X, Chen C, Abdullah AS, Sharma M, Liu H, Zhao Y (2016) Knowledge about and sources of smoking-related knowledge, and influencing factors among male urban secondary school students in Chongqing, China. SpringerPlus 5(1):1879. doi:10.1186/s40064-016-3589-z

\section{Submit your manuscript to a SpringerOpen ${ }^{\circ}$ journal and benefit from:}

- Convenient online submission

- Rigorous peer review

- Immediate publication on acceptance

- Open access: articles freely available online

- High visibility within the field

- Retaining the copyright to your article

Submit your next manuscript at springeropen.com 